\title{
APLIKASI SISTEM KENDALI PERGERAKAN KAMERA BERBASIS ANDROID
}

\author{
F. Shoufika Hilyana \\ Fakultas Teknik, Program Studi Teknik Elektro \\ Universitas Muria Kudus \\ Email: farah.hilyana@umk.ac.id \\ Hasyrul Mirza \\ Fakultas Teknik, Program Studi Teknik Elektro \\ Universitas Muria Kudus \\ Email: hasyrul.mirza@gmail.com \\ Budi Gunawan \\ Fakultas Teknik, Program Studi Teknik Elektro \\ Universitas Muria Kudus \\ Email: budi.gunawan02@gmail.com
}

\begin{abstract}
ABSTRAK
Pengambilan gambar dengan menggunakan banyak kamera digunakan untuk mengambil gambar dengan dua atau lebih kamera, pada setiap pengambilan gambar dari suatu adegan yang sama dengan hasil sudut pandang yang berbeda. Sehingga sumber daya manusia akan banyak yang terlibat. Oleh karena itu dibutuhkan aplikasi yang memudahkan teknik pengambilan gambar oleh kamera dan mengurangi keterlibatan sumber daya manusia, maka tujuan dari penelitian ini adalah terciptanya sistem kendali pergerakan kamera menggunakan kendali berbasis Android. Metode yang digunakan adalah riset dan pengembangan yang meliputi pembuatan hardware, pembuatan software, pengujian, dan pengambilan data. Dalam pengujian data meliputi pengujian gerakan pan, tilt, dan zoom dengan mecari tigkat presentasi error dan akurasi dan pengujian jarak pairing bluetooth. Pengujian menggunakan smartphone android sebagai pengendali. Hasil penelitian pada gerakan pan right tingkat error dengan rata-rata 5,55\% dan akurasi dengan rata-rata 94,45\%, dan untuk gerakan pan left tingkat error dengan rata-rata 4,99\% dan akurasi dengan rata-rata 95,01\%. Pada gerakan tilt up tingkat error dengan rata-rata 7,90\% dan tingkat akurasi rata-rata 92,10\%, gerakan tilt down tingkat error dengan rata-rata 3,99\% dan tingkat akurasi ratarata $96,01 \%$ Pada zoom in tingkat error dengan rata-rata 5,25\% dan tingkat akurasi 94,75\%. Pada pengujian zoom out tingkat error dengan rata-rata 4,57\% dan nilai tingkat akurasi 95,43\%. Dan untuk pengujian jarak pairing bluetooth pada ruang terbuka sampai pada jarak 64 meter dan pengujian jarak pairing pada ruang tertutup sampai pada jarak 9 meter.
\end{abstract}

Kata kunci: sistem kendali; kamera; android.

\begin{abstract}
The technique of taking pictures with multi camera is used to take pictures with two or more cameras at each shooting of the same scene with the results of different angles. So that makes a lot of human resources that will be involved. Therefore we need a tool that facilitates the technique of taking pictures by the camera and reduces the involvement of human resources, the purpose of this study is to produce an automation system on camera movements using the control of an Android smartphone. The method used is research and development which includes hardware manufacturing, software creation, testing, and data retrieval. In testing the data include testing the motion of pan, tilt, and zoom by looking for three levels of presentation error and accuracy, and testing the Bluetooth pairing distance. Testing using an android smartphone as a controller. The results of the study on pan right movements with an average error rate of $5.55 \%$ and accuracy with an average of $94.45 \%$, and for pan left movements the error rate with an average of $4.99 \%$ and accuracy with an average of $95,01 \%$. In the tilt-up movement the error rate with an average of $7.90 \%$ and an average accuracy rate of $92.10 \%$, the movement of the tilt-down error rate with an average of $3.99 \%$ and an average accuracy rate of $96.01 \%$. At zoom in the error rate with an average of $5.25 \%$ and an accuracy rate of $94.75 \%$. In the zoom out test the error rate with an average of $4.57 \%$ and an accuracy rate of $95.43 \%$. And for testing the Bluetooth pairing distance in an open space to a distance of 64 meters and pairing distance testing in an enclosed space to a distance of 9 meters.
\end{abstract}

Keywords: control system; camera; android. 


\section{PENDAHULUAN}

Dalam perkembangan sinematografi yang pesat membuat seorang sinematografer berpikir untuk menciptakan teknik - teknik baru guna untuk mengikuti tuntutan kreatifitas dalam penyampaian kepada penonton. Salah satunya ialah teknik pengambilan gambar dengan banyak kamera disebut juga multi camera. Pada teknik bertujuan untuk mengambil gambar dengan dua atau lebih kamera pada setiap pengambilan gambar dari suatu adegan yang sama dengan hasil sudut pandang yang berbeda [1]. Sinematografi adalah sebuah seni produksi karya cerita audio visual yang bercerita lewat karakter. Kesenian sinematografi hadir untuk mengendalikan apa yang dilihat penonton dan bagaimana gambar dipresentasikan. Sinematografi dapat diartikan kegiatan menangkap gambar gerak dan suara dengan menyampaikan maksud dan tujuan atau informasi atau ide cerita tertentu. Film merupakan hasil dari buah karya dari kegiatan sinematografi, film dikatakan baik dan sukses ialah mampu membuat penonton dapat mengerti isi dan makna cerita tanpa mendengar dialog apapun dari film tersebut [2].

Android adalah sistem operasi yang bersifat open source (sumber terbuka), yakni android dapat menggunakan aplikasi yang sudah dimodifikasi secara bebas dan membuat aplikasi sendiri secara bebas. Dalam pengembangan aplikasi android, kode pemrograman menggunakan bahasa java yang sebagian besar kodenya dirilis oleh Google yaitu berupa java library dengan lisensi Apache, free software dan berbasis open source. Jadi siapa saja bisa menggunakan aplikasi atau membuat tanpa harus mengeluarkan dana [3]. Arduino digunakan sebagai pengendali yang terintegrasi oleh internet dan dalam pergerakan kamera secara pan menggunakan motor servo sebagai penggerak kamera [4]. Pengoperasian kamera dan penggerakan kamera menggunakan handphone berbasis android sebagai antarmuka, hasil gambar yang diambil oleh kamera akan dikirim melalui wifi, dan ditampilkan pada handphone android [5].

Pengendalian kamera DSLR untuk pengambilan gambar melalui protokol PTP, dilakukan dengan menggunakan USB Host Shield, yaitu alat yang yang digunakan sebagai penghubung kamera DSLR dengan arduino melalui antar muka pada komputer. Posisi pergerakan pan dan tilt kamera diatur menggunakan servo dynamixel. Alat ini bekerja dengan perintah melalui command pada serial arduino, dengan perintah untuk dapat mengambil gambar dan menggerakkan kamera [6]. Sistem pergerakan kamera secara otomatis juga pernah dilakukan oleh Putra, Martinus, dan Yahya [7], pengambilan gambar dan pergerakan kamera ini secara autonomus dengan sistem loop, dimana bekerja terus menerus dengan rentang waktu yang ditentukan. Pada pengambilan gambar dan pergerakan kamera pan dan tilt menggunakan motor servo dan arduino sebagai pengendali.

Saat ini teknik multi camera dilakukan dengan pengambilan gambar dengan dua atau lebih kamera dengan dioperasikan oleh satu orang pada satu kamera yang mengakibatkan banyaknya sumber daya manusia yang akan terlibat. Oleh karena itu dibutuhkan sebuah alat yang dikendalikan oleh smartphone android dari jarak jauh dengan gerakan kamera pan left, pan right, tilt up, tilt down, zoom in, dan zoom out. Dengan penelitian alat ini diharapkan mampu meminimalisir sumber daya manusia yang akan terlibat. Dilihat dari permasalahan yang ada dan penelitian sebelumnya, untuk alat pengendali kamera belum adanya dengan pergerakan zoom in, dan zoom out dengan smartphone sebagai pengendali, dalam kesempatan kali ini akan dibuat pengendali kamera dengan menggunakan motor servo dengan pergerakan pan left, pan right, tilt up, tilt down, zoom in, dan zoom out berbasis arduino nano dengan kendali smartphone android.

\section{METODOLOGI PENELITIAN}

Sistem yang dirancang dalam penelitian ini merupakan sistem dengan pengendalian kamera yang digerakkan secara pan, tilt, dan zoom menggunakan motor servo. Pengendalian kamera tersebut dilakukan menggunakan modul arduino nano yang akan terhubung oleh smartphone android dengan wireless. Secara keseluruhan diagram blok sistem ini dapat dilihat pada Gambar 1. Sistem dimulai pada smartphone android memberi perintah dengan software tampilan antar muka yang telah dibuat menggunakan app inventor melalui bluetooth smartphone android kepada modul bluetooth yang terintegrasi dengan arduino nano. Arduino nano akan memberi perintah kepada motor servo untuk menggerakkan sebuah kamera.

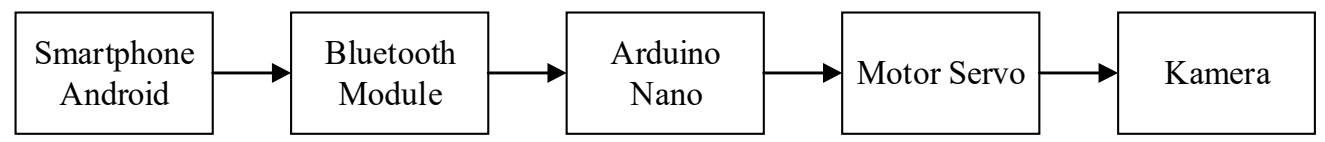

Gambar 1. Diagram Blok Sistem Kendali 


\subsection{Perancangan Sistem Hardware}

Perancangan hardware dilakukan setelah sistem kendali alat telah ditentukan. Perancangan sistem hardware dimulai dari perancangan alat yang terdiri dari aluminium, baut, bearing, pillow bearing, shaft, pulley timing, dan $v$ belt timing. Desain rancangan kerangka alat sistem otomasi pergerakan kamera yang dibangun menggunakan bahan aluminium dapat dilihat pada gambar 2 .

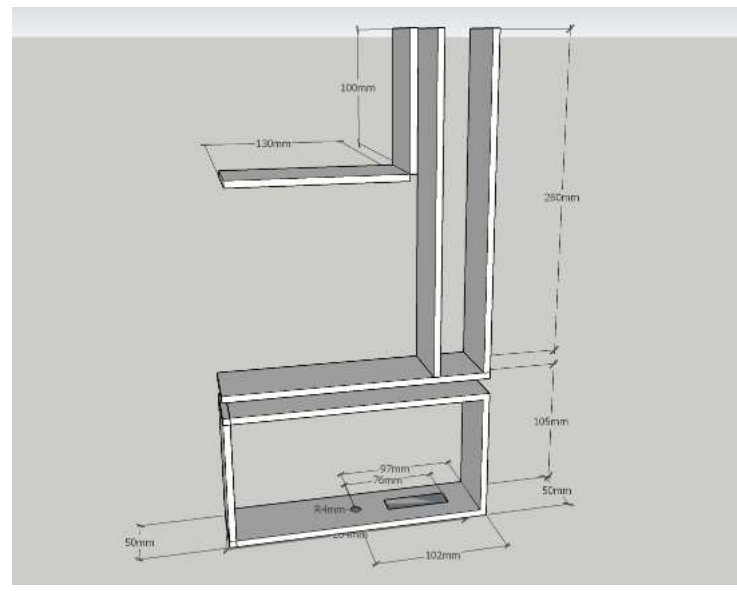

Gambar 2. Desain Rancang Alat

Selanjutnya perancangan rangkaian elektronika yang ditunjukkan pada gambar 3. terdiri dari beberapa komponen yang dihubungkan dengan arduino nano sebagai sistem kendali.

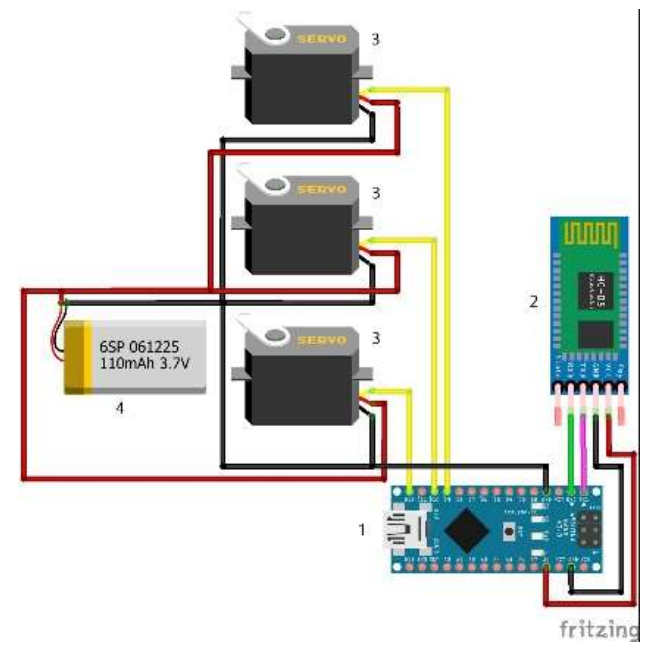

Gambar 3. Desain Rangkaian Elektronika

\subsection{Perancangan Software}

Perancangan software dilakukan dengan dua tahap yaitu, perancangan software pada arduino IDE dan app inventor. Pada perancangan software arduino IDE dibuat untuk menerima data dari android melalui bluetooth dan memerintah motor servo. Pada perancangan software app inventor ada dua tahap yaitu perancangan software antar muka pada android, dan perancangan software script blocks.

\section{HASIL DAN PEMBAHASAN}

\subsection{Hardware yang Dihasilkan}

Penelitian ini telah menghasilkan sebuah alat sistem otomasi pergerakan kamera dengan menggunakan kendali smartphone dengan menggunakan arduino nano sebagai pengendali motor servo, 
dimana motor servo digunakan untuk menggerakkan kamera secara pan, tilt dan menggerakkan lensa kamera untuk zoom in dan zoom out. Gambar 4 menunjukkan alat yang telah selesai dibuat.

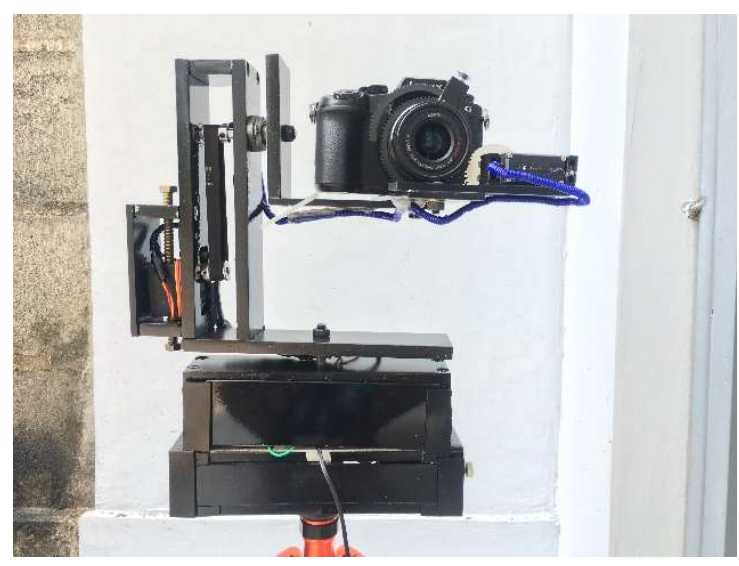

Gambar 4. Sistem Otomasi Pergerakan Kamera dengan Menggunakan Kendali Smartphone

\subsection{Software yang dihasilkan}

Kegiatan penelitian ini telah menghasilkan sebuah software aplikasi untuk smartphone android dengan menggunakan bluetooth sebagai penghubung tanpa kabel yang akan terkoneksi dengan modul bluetooth yang telah dirangkai pada arduino nano. Pada software aplikasi Gambar 5. Menunjukkan aplikasi yang telah selesai dibuat dengan menggunakan metode slider.

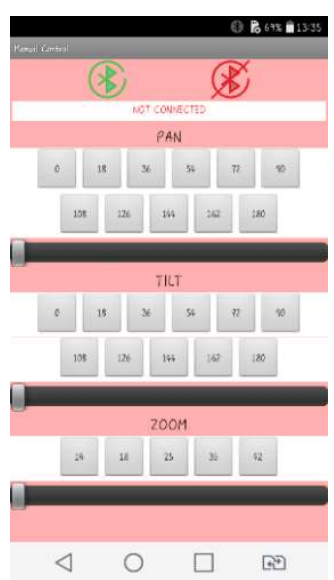

Gambar 5. Aplikasi Sistem Otomasi Pergerakan Kamera dengan Menggunakan Kendali Smartphone dengan Metode Slider

\subsection{Pengujian Gerakan Pan Right dan Pan Left}

Pada tahap pengujian gerakan pan rigtht dilakukan pengujian untuk pergerakan secara horizontal ke arah kanan dan pan left pergerakan secara horizontal ke arah kiri pada kamera, pada pengujian akan dilakukan perbandingan sudut pergerakan alat dengan sudut yang ditentukan dan akan dihitung presentasi error dan presentasi akurasi. Pengujian pergerakan alat dengan gerakan pan right (tabel 1), dengan pergerakan dari sudut $180^{\circ}$ sampai $18^{\circ}$ dengan selisih tiap sudut adalah $18^{\circ}$, mendapatkan nilai akurasi 94,45 $\%$, sedangkan pengujian pergerakan alat dengan gerakan pan left (tabel 2), dengan pergerakan dari sudut $18^{\circ}$ sampai $180^{\circ}$ dengan selisih tiap sudut adalah $18^{\circ}$, mendapatkan nilai akurasi $95,01 \%$.

Tabel 1. Pengujian pergerakan alat dengan gerakan pan right

\begin{tabular}{|c|c|c|c|c|c|c|c|c|c|}
\hline \multirow{2}{*}{ No } & \multirow{2}{*}{$\begin{array}{c}\text { Sudut } \\
\text { Sebenarnya }\end{array}$} & \multicolumn{5}{|c|}{ Sudut terukur } & \multirow{2}{*}{ Rata - rata } & \multirow{2}{*}{ Error \% } & \multirow{2}{*}{ Akurasi \% } \\
\hline & & I & II & III & IV & $\mathbf{V}$ & & & \\
\hline 1 & 180 & 188 & 186 & 185 & 185 & 188 & 186,40 & 3,56 & 96,44 \\
\hline
\end{tabular}




\begin{tabular}{|c|c|c|c|c|c|c|c|c|c|}
\hline \multirow{2}{*}{ No } & \multirow{2}{*}{$\begin{array}{c}\text { Sudut } \\
\text { Sebenarnya }\end{array}$} & \multicolumn{5}{|c|}{ Sudut terukur } & \multirow{2}{*}{ Rata - rata } & \multirow{2}{*}{ Error \% } & \multirow{2}{*}{ Akurasi \% } \\
\hline & & I & II & III & IV & $\mathbf{V}$ & & & \\
\hline 2 & 162 & 165 & 167 & 168 & 166 & 169 & 167,00 & 3,09 & 96,91 \\
\hline 3 & 144 & 147 & 148 & 149 & 147 & 151 & 148,40 & 3,06 & 96,94 \\
\hline 4 & 126 & 129 & 130 & 130 & 128 & 132 & 129,80 & 3,02 & 96,98 \\
\hline 5 & 108 & 111 & 113 & 112 & 111 & 115 & 112,40 & 4,07 & 95,93 \\
\hline 6 & 90 & 95 & 97 & 96 & 95 & 99 & 96,40 & 7,11 & 92,89 \\
\hline 7 & 72 & 76 & 78 & 78 & 76 & 80 & 77,60 & 7,78 & 92,22 \\
\hline 8 & 54 & 56 & 59 & 59 & 58 & 61 & 58,60 & 8,52 & 91,48 \\
\hline 9 & 36 & 35 & 39 & 39 & 38 & 41 & 38,40 & 6,67 & 93,33 \\
\hline 10 & 18 & 16 & 20 & 20 & 18 & 22 & 19,20 & 6,67 & 93,33 \\
\hline \multicolumn{8}{|c|}{ Rata-rata } & 5,55 & 94,45 \\
\hline
\end{tabular}

Tabel 2. Pengujian pergerakan alat dengan gerakan pan left

\begin{tabular}{|c|c|c|c|c|c|c|c|c|c|}
\hline \multirow{2}{*}{ No } & \multirow{2}{*}{$\begin{array}{c}\text { Sudut } \\
\text { Sebenarnya }\end{array}$} & \multicolumn{5}{|c|}{ Sudut terukur } & \multirow{2}{*}{ Rata - rata } & \multirow{2}{*}{ Error \% } & \multirow{2}{*}{ Akurasi \% } \\
\hline & & I & II & III & IV & $\mathbf{V}$ & & & \\
\hline 1 & 18 & 20 & 21 & 20 & 20 & 20 & 20,20 & 12,22 & 87,78 \\
\hline 2 & 36 & 38 & 39 & 40 & 37 & 40 & 38,80 & 7,78 & 92,22 \\
\hline 3 & 54 & 57 & 58 & 58 & 57 & 59 & 57,80 & 7,04 & 92,96 \\
\hline 4 & 72 & 76 & 77 & 77 & 76 & 77 & 76,60 & 6,39 & 93,61 \\
\hline 5 & 90 & 92 & 94 & 94 & 93 & 95 & 93,60 & 4,00 & 96,00 \\
\hline 6 & 108 & 109 & 111 & 110 & 109 & 111 & 110,00 & 1,85 & 98,15 \\
\hline 7 & 126 & 128 & 128 & 128 & 128 & 129 & 128,20 & 1,75 & 98,25 \\
\hline 8 & 144 & 147 & 147 & 147 & 146 & 148 & 147,00 & 2,08 & 97,92 \\
\hline 9 & 162 & 168 & 167 & 166 & 167 & 168 & 167,20 & 3,21 & 96,79 \\
\hline 10 & 180 & 188 & 186 & 185 & 185 & 188 & 186,40 & 3,56 & 96,44 \\
\hline \multicolumn{8}{|c|}{ Rata -rata } & 4,99 & 95,01 \\
\hline
\end{tabular}

\subsection{Pengujian Gerakan Tilt Up dan Tilt Down}

Pada tahap pengujian pergerakan tilt up dilakukan pengujian untuk pergerakan secara vertikal kearah atas dan tilt down dilakukan pengujian untuk pergerakan secara vertikal kearah bawah pada kamera, pada pengujian ini akan dilakukan perbandingan sudut pergerakan alat dengan sudut yang ditentukan dan akan dihitung presentasi error dan presentasi akurasi. Pengujian pergerakan alat dengan gerakan tilt up (tabel 3), dengan pergerakan dari sudut $180^{\circ}$ sampai $18^{\circ}$ dengan selisih tiap sudut adalah $18^{\circ}$, mendapatkan nilai akurasi 92,10\%, sedangkan pengujian pergerakan alat dengan gerakan tilt down (tabel 4), dengan pergerakan dari sudut $18^{\circ}$ sampai $180^{\circ}$ dengan selisih tiap sudut adalah $18^{\circ}$, mendapatkan nilai akurasi $96,01 \%$.

Tabel 3. Pengujian pergerakan alat dengan gerakan tilt up

\begin{tabular}{cccccccccc}
\hline \multirow{2}{*}{ No } & $\begin{array}{c}\text { Sudut } \\
\text { Sebenarnya }\end{array}$ & I & II & III & IV & V & Rata - rata & Error \% & \multirow{2}{*}{ Akurasi \% } \\
\cline { 2 - 7 } & 180 & 180 & 180 & 180 & 180 & 180 & 180,00 & 0,00 & 100,00 \\
2 & 162 & 165 & 166 & 166 & 166 & 165 & 165,60 & 2,22 & 97,78 \\
3 & 144 & 147 & 147 & 147 & 147 & 147 & 147,00 & 2,08 & 97,92 \\
4 & 126 & 130 & 131 & 130 & 130 & 130 & 130,20 & 3,33 & 96,67 \\
5 & 108 & 112 & 113 & 113 & 113 & 112 & 112,60 & 4,26 & 95,74 \\
6 & 90 & 95 & 96 & 95 & 95 & 95 & 95,20 & 5,78 & 94,22
\end{tabular}




\begin{tabular}{cccccccccc}
\hline 7 & 72 & 79 & 78 & 78 & 78 & 78 & 78,20 & 8,61 & 91,39 \\
8 & 54 & 59 & 59 & 59 & 59 & 59 & 59,00 & 9,26 & 90,74 \\
9 & 36 & 41 & 40 & 40 & 41 & 40 & 40,40 & 12,22 & 87,78 \\
10 & 18 & 23 & 22 & 22 & 22 & 22 & 22,20 & 23,33 & 76,67 \\
\hline \multicolumn{7}{c}{ Rata -rata } \\
\hline
\end{tabular}

Tabel 4. Pengujian pergerakan alat dengan gerakan tilt down

\begin{tabular}{|c|c|c|c|c|c|c|c|c|c|}
\hline \multirow{2}{*}{ No } & \multirow{2}{*}{$\begin{array}{c}\text { Sudut } \\
\text { Sebenarnya }\end{array}$} & \multicolumn{5}{|c|}{ Sudut terukur } & \multirow{2}{*}{ Rata - rata } & \multirow{2}{*}{ Error \% } & \multirow{2}{*}{ Akurasi \% } \\
\hline & & $\mathbf{I}$ & II & III & IV & $\mathbf{V}$ & & & \\
\hline 1 & 18 & 20 & 19 & 20 & 19 & 19 & 19,40 & 7,78 & 92,22 \\
\hline 2 & 36 & 39 & 39 & 39 & 39 & 39 & 39,00 & 8,33 & 91,67 \\
\hline 3 & 54 & 58 & 58 & 59 & 58 & 58 & 58,20 & 7,78 & 92,22 \\
\hline 4 & 72 & 77 & 77 & 77 & 77 & 77 & 77,00 & 6,94 & 93,06 \\
\hline 5 & 90 & 93 & 94 & 93 & 93 & 93 & 93,20 & 3,56 & 96,44 \\
\hline 6 & 108 & 111 & 111 & 111 & 111 & 111 & 111,00 & 2,78 & 97,22 \\
\hline 7 & 126 & 127 & 128 & 128 & 127 & 127 & 127,40 & 1,11 & 98,89 \\
\hline 8 & 144 & 144 & 145 & 144 & 144 & 144 & 144,20 & 0,14 & 99,86 \\
\hline 9 & 162 & 162 & 163 & 163 & 162 & 163 & 162,60 & 0,37 & 99,63 \\
\hline 10 & 180 & 177 & 179 & 178 & 178 & 178 & 178,00 & 1,11 & 98,89 \\
\hline \multicolumn{8}{|c|}{ Rata -rata } & 3,99 & 96,01 \\
\hline
\end{tabular}

\subsection{Pengujian Gerakan Zoom In dan Zoom Out}

Pada tahap pengujian gerakan zoom in dan zoom out dilakukan pengujian pada pergerakan lensa kamera, pada pengujian ini akan dilakukan perbandingan focal length yang ditentukan tertera pada lensa kamera dengan focal length yang dicapai dan dihitung presentasi error dan akurasi. Pengujian pergerakan alat dengan gerakan zoom in (tabel 5), dengan pergerakan focal length dari 14 sampai 42 dengan 5 variasi selisih tiap gerakan, mendapatkan nilai akurasi $94,75 \%$, sedangkan pengujian pergerakan alat dengan gerakan zoom out (tabel 6), dengan pergerakan focal length dari 42 sampai 14 dengan 5 variasi selisih tiap gerakan, mendapatkan nilai akurasi 95,43\%.

Tabel 5. Pengujian pergerakan lensa dengan gerakan zoom in

\begin{tabular}{|c|c|c|c|c|c|c|c|c|c|}
\hline \multirow{2}{*}{ No } & \multirow{2}{*}{$\begin{array}{c}\text { Focal Length } \\
\text { Sebenarnya }\end{array}$} & \multicolumn{5}{|c|}{ Focal Length } & \multirow{2}{*}{ Rata - rata } & \multirow{2}{*}{ Error \% } & \multirow{2}{*}{ Akurasi \% } \\
\hline & & $\mathbf{I}$ & II & III & IV & $\mathbf{V}$ & & & \\
\hline 1 & 14 & 15 & 14 & 14 & 14 & 14 & 14,20 & 1,43 & 98,57 \\
\hline 2 & 18 & 20 & 20 & 20 & 20 & 20 & 20,00 & 11,11 & 88,89 \\
\hline 3 & 25 & 27 & 27 & 27 & 27 & 27 & 27,00 & 8,00 & 92,00 \\
\hline 4 & 35 & 37 & 37 & 37 & 37 & 37 & 37,00 & 5,71 & 94,29 \\
\hline 5 & 42 & 42 & 42 & 42 & 42 & 42 & 42,00 & 0,00 & 100,00 \\
\hline \multicolumn{8}{|c|}{ Rata-rata } & 5,25 & 94,75 \\
\hline
\end{tabular}

Tabel 6. Pengujian pergerakan lensa dengan gerakan zoom out

\begin{tabular}{|c|c|c|c|c|c|c|c|c|c|}
\hline \multirow{2}{*}{ No } & \multirow{2}{*}{$\begin{array}{l}\text { Focal Length } \\
\text { Sebenarnya }\end{array}$} & \multicolumn{5}{|c|}{ Focal Length } & \multirow{2}{*}{ Rata - rata } & \multirow{2}{*}{ Error \% } & \multirow{2}{*}{ Akurasi \% } \\
\hline & & $\mathbf{I}$ & II & III & IV & $\mathbf{V}$ & & & \\
\hline 1 & 42 & 42 & 42 & 42 & 42 & 42 & 42,00 & 0,00 & 100,00 \\
\hline 2 & 35 & 37 & 36 & 36 & 36 & 36 & 36,20 & 3,43 & 96,57 \\
\hline 3 & 25 & 27 & 27 & 27 & 27 & 27 & 27,00 & 8,00 & 92,00 \\
\hline 4 & 18 & 20 & 20 & 20 & 20 & 19 & 19,80 & 10,00 & 90,00 \\
\hline
\end{tabular}




\begin{tabular}{cccccccccc}
5 & 14 & 14 & 15 & 14 & 14 & 14 & 17,20 & 1,43 & 98,57 \\
\hline \multicolumn{10}{c}{ Rata -rata } \\
\hline 3.6 & $P e n g u j a n$ & & & & 4,57 & 95,43 \\
\hline
\end{tabular}

\subsection{Pengujian Jarak Bluetooth}

Pada tahap pengujian jarak pada bluetooth ditunjukkan untuk jarak pairing bluetooth modul HC-05 dengan android. Pengujian jarak pairing bluetooth dilakukan di ruang terbuka dan ruang tertutup. Pada ruang terbuka (tabel 7) jangkauan Bluetooth tersambung sampai jarak 60 meter, dan mulai jarak 65 meter dan seterusnya bluetooth tidak tersambung lagi. Sedangkan pada ruang tertutup (tabel 8), jangkauan bluetooth tersambung hingga jarak 8 meter, dan dari jarak 10 meter dan seterusnya bluetooth tidak dapat tersambung.

Tabel 7. Pengujian jarak pairing bluetooth pada ruang terbuka

\begin{tabular}{cc}
\hline Jarak (Meter) & Status \\
\hline 10 & Connected \\
20 & Connected \\
30 & Connected \\
40 & Connected \\
50 & Connected \\
60 & Connected \\
65 & Not Connected \\
70 & Not Connected \\
\hline
\end{tabular}

Tabel 8. Pengujian jarak pairing bluetooth pada ruang tertutup

\begin{tabular}{cc}
\hline Jarak (Meter) & Status \\
\hline 2 & Connected \\
4 & Connected \\
6 & Connected \\
8 & Connected \\
10 & Not Connected \\
\hline
\end{tabular}

Sehingga dapat dikatakan bahwa alat sistem otomasi penggerak kamera dengan menggunakan kendali smartphone, dapat bekerja sesuai yang diharapkan, baik pada gerakan pan, tilt, dan zoom.

\section{KESIMPULAN}

Dari hasil penelitian yang telah dilakukan dapat diambil kesimpulan sebagai berikut :

a. Telah berhasil dibuat alat sistem otomasi penggerak kamera dengan menggunakan kendali smartphone.

b. Hasil pengujian yang telah dilakukan pada pergerakan kamera pan right mempunyai error $5,55 \%$ dengan akurasi $94,45 \%$, pada pergerakan kamera pan left mempunyai error 4,99\% dengan akurasi $95,01 \%$, pada pergerakan kamera tilt up mempunyai error 7,90\% dengan akurasi $92,10 \%$, pada pergerakan kamera tilt down mempunyai error 3,99\% dengan akurasi 96,01\%, sedangkan pada pergerakan lensa zoom in mempunyai error $5,25 \%$ dengan akurasi $94,75 \%$ dan pada pergerakan lensa zoom out mempunyai error $4,57 \%$ dengan akurasi $95,43 \%$, sehingga alat yang dibuat sesuai dengan yang diharapkan.

c. Hasil pengujian yang telah dilakukan pada jarak pairing bluetooth, untuk ruang terbuka pada jarak terdekat dengan alat sampai dengan 64 meter koneksi tersambung. Sedangkan pada ruang tertutup pada jarak terdekat dengan alat sampai dengan 9 meter koneksi tersambung.

\section{DAFTAR PUSTAKA}

[1] A. Purwanto, "Teknik Editing Video dengan Multi Kamera," J. DASI, vol. 12, no. 2, pp. 7-15, 2011. 
[2] T. Heiderich, Cinematography Techniques: The Different Types of Shots in Film. Videomaker, 2012.

[3] F. K and G. W, Cepat Menguasai Pemrograman Android. Malang: Universitas Brawijaya Press, 2015.

[4] Rinaldy, R. F. Christianti, and D. Supriyadi, "Pengendalian Motor Servo Yang Terintegrasi Dengan Webcam Berbasis Internet Dan Arduino,” J. Infotel, vol. 5, no. 2, pp. 17-23, 2013.

[5] L. de J. Silva, A. Joewono, and A. Wibowo, "Mengendalikan Kamera IP dengan Menggunakan Handphone Berbasis Android,” Widya Tek., vol. 12, no. 1, pp. 22-35, 2013.

[6] M. Iqbal, T. W. Widodo, and B. A. A. Sumbodo, "Sistem Pengendali Pengambilan Gambar Pada Kamera DSLR Melalui Protokol PTP,” IJEIS, vol. 6, no. 2, pp. 117-128, 2016.

[7] D. K. Putra, Martinus, and A. Yahya, "Pembuatan Sistem Robotika Sebagai Implementasi Pergerakan Kamera Secara Autonomous," J. FEMA, vol. 2, no. 2, pp. 23-30, 2014. 